\title{
INDIRECT SPECTROPHOTOMETRIC METHOD FOR DETERMINATION OF CAPTOPRIL USING CR(VI) AND DIPHENYLCARBAZIDE
}

\author{
Zenovia Moldovan and Irinel Adriana Badea \\ Department of Analytical Chemistry, Faculty of Chemistry, University of Bucharest, 92-96, Sos. Panduri, Bucharest-5, 050663, \\ Romania \\ Andrei A. Bunaciu \\ CROMATEC_PLUS SRL, Analytical Research Department, 18 Sos. Cotroceni, Bucharest - 6, 060114, Romania \\ Hassan Y. Aboul-Enein* \\ Pharmaceutical and Medicinal Chemistry Department, Pharmaceutical and Drug Industries Research Division, National Research \\ Centre, Dokki, Cairo 12311, Egypt
}

Recebido em 21/9/11; aceito em 6/4/12, publicado na web em 3/7/12

\begin{abstract}
A spectrophotometric method for the indirect determination of captopril (CP) in pharmaceutical formulations is proposed. The proposed procedure is based on the oxidation of captopril by potassium dichromate and the determination excess oxidant on the basis of its reaction with diphenylcarbazide (DPC). Under the optimum conditions, a good linear relationship $(r=0.9997)$ was obtained in the range of $0.08-3.5 \mu \mathrm{g} \mathrm{mL} \mathrm{m}^{-1}$. The assay limits of detection and quantitation were 0.024 and $0.08 \mu \mathrm{g} \mathrm{mL}^{-1}$, respectively. The results obtained for captopril determination in pharmaceuticals using the proposed method and those obtained with the US Pharmacopoeia method were in good agreement at the $95 \%$ confidence level.
\end{abstract}

Keywords: captopril; diphenylcarbazide; spectrophotometric determination.

\section{INTRODUCTION}

Captopril, (CP, 1-[(2S)-3-mercapto-2-methyl-L-oxopropyl]-Lproline, Figure 1) belongs to the group of anti-hypertensive drugs that affect the renin-angiotensin system and are commonly referred to as angiotensin converting enzyme (ACE) inhibitors. This drug interacts with ACE due to its similarity with a dipeptide where the sulphydryl group also plays an important role, linking covalently to the zinc atom in the enzyme active site. It is a well known drug applied in the treatment of hypertension, coronary heart disease and congestive heart failure following myocardial infarction as well as in diabetic nephropathy. ${ }^{1,2}$<smiles>CC(CS)C(=O)N1CCCC1C(=O)O</smiles>

Figure 1. Structural formula of $C P$

Many analytical methods have been developed for CP determination, such as visual titrimetry, ${ }^{3}$ electrometric methods, ${ }^{4-8}$ capillary electrophoresis, ${ }^{9}$ capillary isotachophoresis, ${ }^{10}$ flow injection analysis, ${ }^{11}$ and chromatographic methods. ${ }^{12-17}$ The most widely used technique for captopril determination is high-performance liquid-chromatography. ${ }^{13,15,16}$ Although the technique is rapid and sensitive it often involves precolumn derivatization ${ }^{12,13,15,17}$ and multiple extraction steps. Gas chromatographic methods reported for determining CP in dosage forms also involve derivatization besides being poorly sensitive. ${ }^{17}$ Captopril has also been determined by spectrometric methods such as: FT-Raman spectroscopy, ${ }^{2}$ fluorimetry, ${ }^{18}$ atomic absorption spectrometry. ${ }^{19}$ Numerous spectrophotometric methods have also been proposed for $\mathrm{CP}$ determination. ${ }^{1,20-33}$ Generaly, these

*e-mail: haboulenein@yahoo.com approaches involve the use of reagents that react with this compound to form species with absorb in the visible region.

The US Pharmacopoeia recommends volumetric and HPLC methods for the assay in bulk and tablet formulations. ${ }^{34}$ The volumetric procedure is based on captopril titration in acid medium using an iodine solution in the presence of excess iodide, with starch as an indicator. Although precise and exact, the procedure is time-consuming. HPLC procedures need expensive and complex equipment while also consume significant amounts of solvents. These drawbacks hinder the use of these procedures for routine analysis.

The methods based on modern instrumental techniques, although sensitive, require expensive instruments and maintenance and also involve several manipulation steps and derivatization reactions. Also, some spectrophotometric methods suffer from disadvantages such as low sensitivity, long reaction time for color development (>30 min), and require prior extraction of the colored product or involve boiling the reaction mixture for a significant period of time.

This paper describes a new highly sensitive spectrophotometric method for the determination of CP. The method is based on its oxidation by dichromate, in acid medium, followed by estimation of the oxidant excess by reacting with diphenylcarbazide and measuring the absorbance of the complex at $\lambda_{\max }=540 \mathrm{~nm}$. The proposed method was compared with other reported spectrophotometric methods and found to be more sensitive than previously reported techniques. The proposed method was validated for accuracy, precision and recovery and was applied for determination of CP in tablets. Results were in strong agreement with those obtained by the official method contained in the US Pharmacopoeia. ${ }^{34}$

\section{EXPERIMENTAL}

\section{Chemicals and instrument for spectrometric measurements}

All chemicals were of analytical reagent grade. Doubly-distilled water was used throughout. A $0.01 \mathrm{~mol} \mathrm{~L}^{-1} \mathrm{~K}_{2} \mathrm{Cr}_{2} \mathrm{O}_{7}$ stock solution 
was prepared by dissolving $0.735 \mathrm{~g}$ of $\mathrm{K}_{2} \mathrm{Cr}_{2} \mathrm{O}_{7}$ (Merck Chemical Co. Germany) in water and diluting to $250 \mathrm{~mL}$ in a calibrated flask. A working concentration of $10^{-4} \mathrm{~mol} \mathrm{~L}^{-1} \mathrm{~K}_{2} \mathrm{Cr}_{2} \mathrm{O}_{7}$ was prepared by appropriate dilution of stock solution with water. A $1 \%$ diphenylcarbazide solution was prepared by dissolving $1 \mathrm{~g}$ of reagent (BDH Chemicals Ltd., Poole, England) in $100 \mathrm{~mL}$ acetone:water (1:1v/v). Sulfuric acid ( 8 and $4 \mathrm{~mol} \mathrm{~L}^{-1}$ ) solutions were prepared by diluting appropriate volumes (43 and $21.5 \mathrm{~mL}$ respectively) of concentrated acid (Merck, sp. gr. $1.84 \mathrm{~g} / \mathrm{cm}^{3}$ ) to $100 \mathrm{~mL}$ with cooling. An $8 \mathrm{~mol} \mathrm{~L}^{-1}$ hydrochloric acid was prepared by diluting $67 \mathrm{~mL}$ of concentrated acid (Merck, sp. gr. 1.18) to $100 \mathrm{~mL}$. An $8 \mathrm{~mol} \mathrm{~L}^{-1}$ phosphoric acid was prepared by diluting $54 \mathrm{~mL}$ of concentrated acid (Merck, sp. gr. 1.71) to $100 \mathrm{~mL}$.

Captopril standard (purity $>99.9 \%$ ) (CP) was supplied by Fluka, Buchs-Switzerland; while Captopril tablets (Terapia, S.A, Romania) labeled as containing $25 \mathrm{mg}$ captopril were purchased from the local market. Likewise, the tablets were purchased from the local market. A stock standard CP solution $\left(10^{-3} \mathrm{~mol} \mathrm{~L}^{-1}\right)$ was prepared by dissolving $54.3 \mathrm{mg}$ captopril in water to a final volume of $250 \mathrm{~mL}$ and used for preparing a working standard solution of $10^{-4} \mathrm{~mol} \mathrm{~L}^{-1}$. The reference solutions were prepared in the range $0.01-0.24 \times 10^{-4} \mathrm{~mol} \mathrm{~L}^{-1}$ (equivalent to $0.2-5.2 \mu \mathrm{g} \mathrm{mL}^{-1} \mathrm{CP}$ ) using the working solution of $\mathrm{CP} 10^{-4}$ mol L ${ }^{-1}$. Various Eppendorf pipettes (10-100; 100-1000 and 500-2500 $\mu \mathrm{L}$ ) were used to deliver accurate volumes while the absorbance measurements were performed on a UV-VIS spectrophotometer Jasco V-530 apparatus (Jasco, Japan) using quartz cells of 1-cm path length. FTIR spectra were recorded as $\mathrm{KBr}$ pellets by using a Spectrum Two spectrophotometer (Perkin Elmer Co., Beaconsfield, Bucks, UK).

\section{Chemicals and chromatographic conditions}

A stock solution containing $20 \mathrm{mg} \mathrm{mL}^{-1}$ of captopril standard (purity $>99.9 \%$ ) was prepared in mobile phase. This solution was used for preparing working solution of captopril having concentrations in the range 6-13 $\mathrm{mg} \mathrm{mL}^{-1}$ necessary for the linearity studies.

A HPLC Finnagan Surveyor system was used for chromatographic analysis. The system had a quaternary pump, an on-line degasser, automatic injector along with column and sample tray thermostat. Detection was carried out using a Photodiode Array Detector (PDA) with a cell length of $50 \mathrm{~mm}$. The chromatographic system was controlled by ChromQuest software.

The ultra-pure water $(18 \mathrm{M} \Omega / \mathrm{cm})$ was produced using an Ultra Clear system. The $\mathrm{pH}$ of the buffer solutions was measured using a $\mathrm{pH} / \mathrm{mV}$-meter Consort P501, equipped with a combined $\mathrm{pH}$ electrode.

\section{General procedure for proposed method}

An aliquot of standard stock solution equivalent to 0.04-5.2 $\mu \mathrm{g}$ $\mathrm{mL}^{-1}\left(0.002-0.24 \times 10^{-4} \mathrm{~mol} \mathrm{~L}^{-1}\right) \mathrm{CP}, 0.1 \mathrm{~mL}$ of sulfuric acid solution $8 \mathrm{~mol} \mathrm{~L}^{-1}$ and $0.6 \mathrm{~mL}$ of potassium dichromate $10^{-4} \mathrm{~mol} \mathrm{~L}^{-1}$ were transferred into a quartz cell. This mixture was adjusted to $2 \mathrm{~mL}$ by adding bidistilled water. The cell was stoppered, mixed well and then occasionally for $15 \mathrm{~min}$. In the second step, $2.9 \mathrm{~mL}$ of water and $0.1 \mathrm{~mL}$ of DPC $1 \%$ were added (final volume $=5 \mathrm{~mL}$ ). The cell was stoppered, mixed well and absorbance measured at $540 \mathrm{~nm}$, after 5 min, against water as the reference. Blank experiments were also performed by adding bidistilled water instead of $\mathrm{CP}$ solutions. The difference between the absorbance of samples in the presence and absence of CP was taken into consideration.

\section{Procedure for recovery tests}

The validity of the proposed method was confirmed by recovery studies using the standard addition method. For this purpose, a known amount of drug powder $(25 \mathrm{mg})$ equivalent to $4.4 \mathrm{mg}$ of $\mathrm{CP}$ was weighed accurately. After dissolution of the active principle in water, the sample was filtered and quantitatively transferred into a $200 \mathrm{~mL}$ calibrated flask, with doubly-distilled water. Subsequently, known volumes $(0.25$ and $0.5 \mathrm{~mL})$ of the stock standard solution of pure $\mathrm{CP}\left(22 \mu \mathrm{g} \mathrm{mL}^{-1}\right)$ were added to known volumes $(0.25 \mathrm{~mL})$ of the sample solution and the general procedure was then applied.

\section{Procedure for determination of captopril in pharmaceutical formulation}

The applicability of the proposed method for the determination of $\mathrm{CP}$ was tested using the captopril pharmaceutical formulation. For this purpose, ten captopril tablets were accurately weighed and ground into fine powder. The average weight of tablets was calculated. An accurately weighed portion of the resulting powder, equivalent to $4.4 \mathrm{mg}$ of CP was dissolved in water. The resultant solution was then filtered through a Whatman no. 42 filter paper directly into a $200 \mathrm{~mL}$ standard volumetric flask. The residue was washed three times with water for complete recovery of the drug. The washings were added to the volumetric flask which was then filled to the mark with the same solvent. Aliquots of the solution were analyzed as described earlier.

\section{Chromatographic procedure}

The procedure applied in this study was adapted according to the USP 25 monograph assay for captopril tablets. ${ }^{34}$ The mobile phase consisted of methanol:water (with $0.5 \mathrm{~mL} \mathrm{H}_{3} \mathrm{PO}_{4} 85 \%$ ) mixed at proportion of 55:45 (v/v) and was delivered at a flow rate of $1 \mathrm{~mL} /$ min. The column used was a $250 \times 25 \mathrm{~mm}$ HypersilGold packed with C18 stationary phase. Detection was done at $220 \mathrm{~nm}$.

\section{Preparation of reaction product between $\mathrm{CP}$ and $\mathrm{Cr}(\mathrm{VI})$ for infrared (IR) measurements}

Aqueous solutions of $\mathrm{CP}, \mathrm{H}_{2} \mathrm{SO}_{4}$ and $\mathrm{Cr}(\mathrm{VI})$ were transferred into a $10-\mathrm{mL}$ calibrated flask and diluted to the mark, to obtain the following concentration: $[\mathrm{CP}]=10^{-3} \mathrm{~mol} \mathrm{~L}^{-1} ; \mathrm{Cr}(\mathrm{VI})=0.5 \times 10^{-3} \mathrm{~mol}$ $\mathrm{L}^{-1} ;\left[\mathrm{H}_{2} \mathrm{SO}_{4}\right]=0.4 \mathrm{~mol} \mathrm{~L}^{-1}$. The mixture was shaken occasionally for $20 \mathrm{~min}$. The obtained oxidation product between $\mathrm{CP}$ and $\mathrm{Cr}(\mathrm{VI})$ was then extracted in $\mathrm{CH}_{2} \mathrm{Cl}_{2}$. After elimination of the solvent (under vacuum conditions), the dried material was analyzed by Fourier Transform Infrared Spectroscopy (FTIR). The oxidation product was also analyzed by the HPLC method.

\section{RESULTS AND DISCUSSION}

It is well known that captopril, owing to the presence of the thiol group (-SH) in its structure, undergoes redox reaction with different oxidants in acid media, such as Fe(III), ${ }^{20,27,30} \mathrm{Ce}(\mathrm{IV}) ;{ }^{18} \mathrm{Mn}(\mathrm{VII}),{ }^{25}$ bromine, generated in situ by the action of acid on a bromate-bromide mixture, ${ }^{26} \mathrm{KBrO}_{3},{ }^{28} \mathrm{KIO}_{3},{ }^{22}$ chloramine-T. ${ }^{21,23}$ In this work, dichromate was chosen as the oxidative agent. The ability of $\mathrm{Cr}(\mathrm{VI})$ to oxidize the $\mathrm{CP}$ was exploited for indirect determination of the drug. One of the most well-known spectrophotometric methods for $\mathrm{Cr}(\mathrm{VI})$ determination is based on the formation of an intense purple color product with diphenylcarbazide (DPC) in sulfuric acid medium, and measurable at $540 \mathrm{~nm} \cdot{ }^{35}$ When $\mathrm{CP}$ is added in increasing concentrations to a fixed concentration of dichromate consumes the latter. Figure 2 shows that addition of diphenylcarbazide decreases concentrations of dichromate; while absorbance decreases with increasing concentration of $\mathrm{CP}$ giving the correlation coefficient of 0.9997. Preliminary experiments revealed that $0.12 \times 10^{-4} \mathrm{~mol} \mathrm{~L}^{-1}$ 
$\mathrm{K}_{2} \mathrm{Cr}_{2} \mathrm{O}_{7}$ could be determined under the specified acid and reagent concentrations. Hence, different amounts of $\mathrm{CP}$ were reacted with $0.6 \mathrm{~mL}$ of $10^{-4} \mathrm{~mol} \mathrm{~L}^{-1} \mathrm{~K}_{2} \mathrm{Cr}_{2} \mathrm{O}_{7}$, and after the oxidation reaction was complete, unreacted dichromate levels were determined by treating with diphenylcarbazide, and measuring absorbance at $540 \mathrm{~nm}$. This procedure enabled the concentration range of $\mathrm{CP}$ determinable by the method to be established. The experimental parameters such as concentration of $\mathrm{Cr}(\mathrm{VI})$, type and acid concentration, $\mathrm{CP}-\mathrm{Cr}(\mathrm{VI})$ reaction time, were optimized, and the optimum conditions were specified in the recommended procedure.

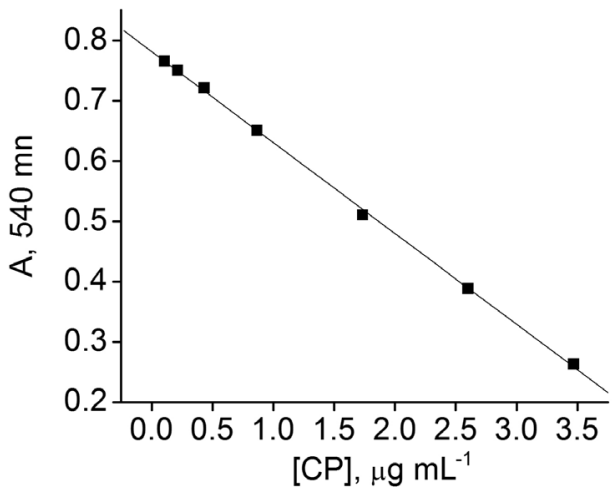

Figure 2. Variation of absorbance of DPC-Cr(VI) product in the presence of different concentrations of captopril. $\left[\mathrm{K}_{2} \mathrm{Cr}_{2} \mathrm{O}_{7}\right]=0.12 \times 10^{-4} \mathrm{~mol} \mathrm{~L}^{-1}$

\section{Effect of acid type on oxidation of $\mathrm{CP}$ by $\mathrm{Cr}(\mathrm{VI})$}

In order to obtain a minimum absorbance of DPC-Cr (VI) reaction product, the experiments were performed on mixtures prepared in $\mathrm{HCl}, \mathrm{H}_{2} \mathrm{SO}_{4}$ and $\mathrm{H}_{3} \mathrm{PO}_{4}$ medium, respectively. Nitric acid was not tested because it is an oxidizing agent and would interfere with the oxidation step. For this purpose, in the first step, mixtures of $0.6 \mathrm{~mL}$ $10^{-4} \mathrm{~mol} \mathrm{~L}^{-1} \mathrm{CP}+0.6 \mathrm{~mL} 10^{-4} \mathrm{~mol} \mathrm{~L}^{-1} \mathrm{Cr}(\mathrm{VI})+0.1 \mathrm{~mL} \operatorname{acid}\left(8 \mathrm{~mol} \mathrm{~L}^{-1}\right)$ + water (up $2 \mathrm{~mL}$ ) were prepared to reach the acidity of $0.4 \mathrm{~mol} \mathrm{~L}^{-1}$. Subsequently, $2.9 \mathrm{~mL}$ of water and $0.1 \mathrm{~mL}$ of DPC $1 \%$ were added to complete the working mixture (up to $5 \mathrm{~mL}$ ) and reach the acidity suitable for spectrophotometric measurement. As can be deduced from Figure 3, the oxidation step of $\mathrm{CP}$ by $\mathrm{Cr}(\mathrm{VI})$ was slow in hydrochloric acid or phosphoric acid medium, yet significant using sulfuric acid. Thus, sulfuric acid was selected as the medium for the oxidation of CP by dichromate.

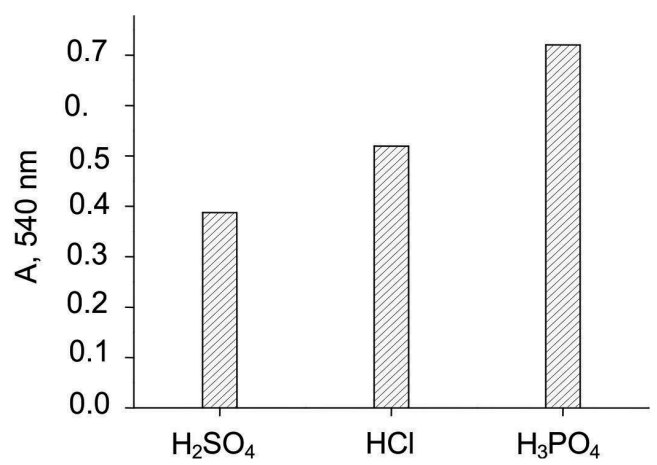

Figure 3. Effect of acid type on the oxidation of $\mathrm{CP}$ by $\mathrm{Cr}(\mathrm{VI})$. $[\mathrm{CP}]=0.12 x$ $10^{-4} \mathrm{~mol} \mathrm{~L}^{-1} ;\left[\mathrm{K}_{2} \mathrm{Cr}_{2} \mathrm{O}_{7}\right]=0.12 \times 10^{-4} \mathrm{~mol} \mathrm{~L}^{-1}$

\section{Effect of $\mathrm{H}_{2} \mathrm{SO}_{4}$ concentration on reaction between $\mathrm{CP}$ and Cr(VI)}

The original procedure for $\mathrm{Cr}(\mathrm{VI})$ using diphenylcarbazide employed a $0.1 \mathrm{~mol} \mathrm{~L}^{-1}$ sulfuric acid concentration. Preliminary experiments showed that the absorbance value of the purple color product between diphenylcarbazide (DPC) and $\mathrm{Cr}(\mathrm{VI})$ was constant in acid medium, in the range 0.1-0.2 mol L-1 $\mathrm{H}_{2} \mathrm{SO}_{4}$. The effect of $\mathrm{H}_{2} \mathrm{SO}_{4}$ concentration on the oxidation of $\mathrm{CP}$ by $\mathrm{Cr}(\mathrm{VI})$ was studied from 0.1 to $0.5 \mathrm{~mol} \mathrm{~L}^{-1}$ sulfuric acid solution and $0.12 \times 10^{-4} \mathrm{~mol} \mathrm{~L}^{-1} \mathrm{CP}$ solution. In the first step, mixtures of $0.6 \mathrm{~mL}$

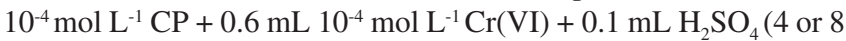
$\mathrm{mol} \mathrm{L}-1)+$ water were prepared by varying the acidity between $0.1-0.5$ mol L ${ }^{-1}$. Subsequently, $0.1 \mathrm{~mL}$ of DPC $1 \%$ and water were added to complete the working mixture (up to $5 \mathrm{~mL}$ ) and to reach the acidity suitable for the spectrophotometric measurement $\left(0.1-0.2 \mathrm{~mol} \mathrm{~L}^{-1}\right.$ $\mathrm{H}_{2} \mathrm{SO}_{4}$ ). As shown in Figure 4, the analytical signal decreased with increased concentration of $\mathrm{H}_{2} \mathrm{SO}_{4}$ up to $0.40 \mathrm{~mol} \mathrm{~L}^{-1}$ and remained almost constant for higher concentrations. Thus, in the first step, mix-

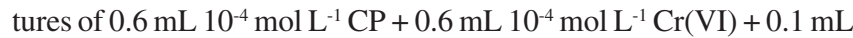
$\mathrm{H}_{2} \mathrm{SO}_{4}\left(8 \mathrm{~mol} \mathrm{~L}^{-1}\right)+$ water (up $2 \mathrm{~mL}$ ) were prepared for further work.

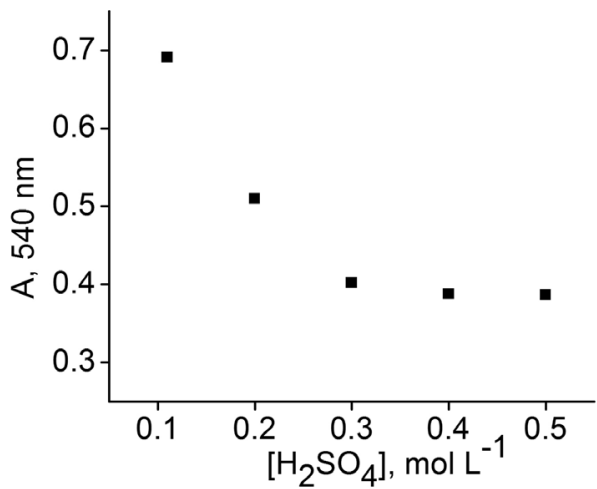

Figure 4. Effect of $\mathrm{H}_{2} \mathrm{SO}_{4}$ concentration on the oxidation of $\mathrm{CP}$ by $\mathrm{Cr}(\mathrm{VI})$. $[C P]=0.12 \times 10^{-4} \mathrm{~mol} \mathrm{~L}^{-1} ;\left[\mathrm{K}_{2} \mathrm{Cr}_{2} \mathrm{O}_{7}\right]=0.12 \times 10^{-4} \mathrm{~mol} \mathrm{~L}^{-1}$

\section{Effect of time on oxidation of $\mathrm{CP}$ by $\mathrm{Cr}(\mathrm{VI})$}

The oxidation time of $\mathrm{CP}$ by dichromate was determined by applying the recommended procedure for spectrometric measurements, under the following conditions: by varying the time of CP-dichromate reaction $\left(\mathrm{t}_{1}=0.5-30 \mathrm{~min}\right.$, at $2.5 \mathrm{~min}$ intervals $)$, for a fixed duration of CP-DPC reaction $\left(t_{2}=5 \mathrm{~min}\right)$. The absorbance measurement started at $30 \mathrm{~s}$ after adding the dichromate solution. The absorbance time profile of CP-Cr(VI)-DPC mixture showed full color decrease after 15 min. Hence the reaction time of $\mathrm{CP}$ with $\mathrm{Cr}(\mathrm{VI})$ of 5 min was chosen for further experiments.

\section{Mechanism of reaction between $\mathrm{CP}$ and $\mathrm{Cr}(\mathrm{VI})$}

From this study, it can be implied that reduced CP (noted R-SH) is oxidized to its disulphide derivative, following the reaction scheme:

$$
6 \mathrm{R}-\mathrm{SH}+\mathrm{Cr}_{2} \mathrm{O}_{7}^{2-}+8 \mathrm{H}^{+} \rightarrow 3 \mathrm{R}-\mathrm{S}-\mathrm{S}-\mathrm{R}+2 \mathrm{Cr}^{3+}+7 \mathrm{H}_{2} \mathrm{O}
$$

Captopril, as for all thiols, was expected to undergo some degree of oxidative degradation such as the formation of disulphide, ${ }^{36}$ as can be seen from the FTIR spectra, Figure 5a, where the characteristic band of S-H, from $2566 \mathrm{~cm}^{-1}$ disappears. A new band, characteristic for S-S frequency, appears in the spectra (Figure 5b), at $622 \mathrm{~cm}^{-1}$.

Using the HPLC method described in the experimental section, the oxidation product of the $\mathrm{CP}$ was also subjected to chromatographic analysis. The HPLC method applied to the CP reference substance reveals a single peak having a retention time at $4.01 \mathrm{~min}$. The oxidized product of $\mathrm{CP}$ extracted in $\mathrm{CH}_{2} \mathrm{Cl}_{2}$ and dried under vacuum conditions 


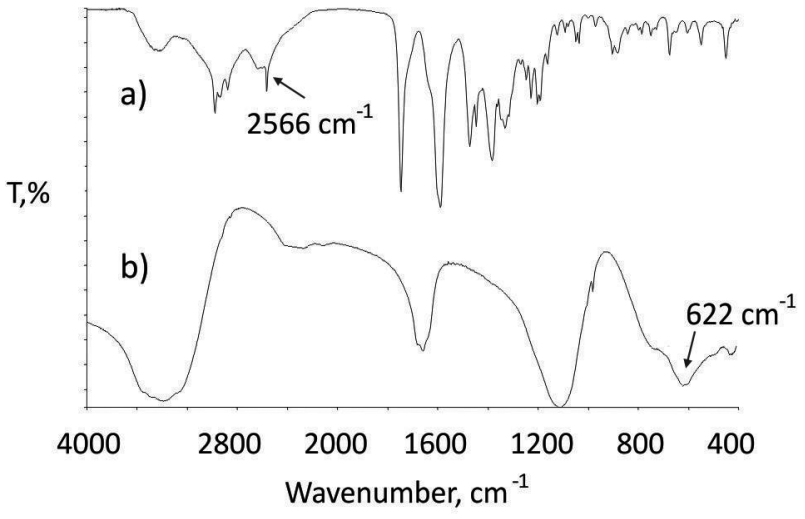

Figure 5. FTIR spectra of captopril standard (a) and its oxidized form (b)

was dissolved in mobile phase. The chromatogram recorded for this compound shows two peaks: one located at $4.01 \mathrm{~min}$ (having an area diminished by $93.34 \%$ ) and another one peak at $5.48 \mathrm{~min}$. This new peak can be considered as corresponding to a compound having a $-\mathrm{S}-\mathrm{S}-$ moiety (Figure 6). This hypothesis is sustained by the chromatographic behavior of such compounds under the specific conditions of this HPLC method: the existence of a-S-S- group denotes high retention of such a compound and represents the case observed in this experiment.

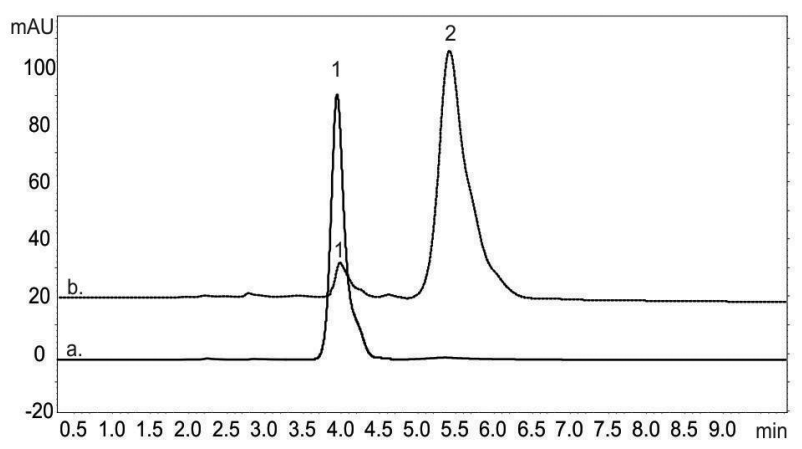

Figure 6. Chromatograms recorded for: (a) CP standard; (b) oxidized product of CP; peaks attributed to: 1 - CP; 2 - oxidized product of $C P$

\section{Analytical parameters of spectrophotometric method}

Analytical characteristics obtained under the optimum experimental conditions are shown in Table 1. A comparison between the proposed method and other reported methods is shown in Table 2. As can be seen in this table, some of the reported procedures have higher detection limits. ${ }^{21,25,28-30,33}$ Limit of detection (LOD) and limit of quantification (LOQ) were calculated as follows: ${ }^{37} \mathrm{LOD}=3 \mathrm{~s} / \mathrm{b}$; $\mathrm{LOQ}=10 \mathrm{~s} / \mathrm{b}$, where $\mathrm{b}$ is the slope of the analytical curve and $\mathrm{s}$ is 10 measurements of the blank solutions. Moreover, some of the reported methods are alike or more sensitive but have drawbacks such as having a narrow linear dynamic range, ${ }^{18,24,27,33}$ or involving organic solvents ${ }^{13,30}$ and heating. ${ }^{24}$

Table 1. Statistical data for the regression equation of the proposed method

\begin{tabular}{lc}
\hline Parameter & Value \\
\hline$\lambda_{\max }, \mathrm{nm}$ & 540 \\
Linear range $\left(\mu \mathrm{g} \mathrm{mL}{ }^{-1}\right)$ & $0.1-3.5$ \\
Correlation coefficient $(\mathrm{r})$ & 0.9997 \\
Linear regression equation & $\mathrm{A}=-0.1509 \mathrm{x}[\mathrm{CP}]^{\mathrm{a}}+0.7816$ \\
Standard deviation of the regression line $\left(\mathrm{s}_{\mathrm{o}}\right)$ & 0.006 \\
$\mathrm{LOD}\left(\mu \mathrm{gL}^{-1}\right)$ & 0.024 \\
$\mathrm{LOQ}\left(\mu \mathrm{gL}^{-1}\right)$ & 0.08 \\
\hline
\end{tabular}

${ }^{\mathrm{a}}$ Concentration of $\mathrm{CP}\left(\mu \mathrm{g} \mathrm{mL} \mathrm{m}^{-1}\right)$

\section{Accuracy and precision}

In order to study the accuracy and precision of the proposed method, three concentrations of $\mathrm{CP}$ within the linearity range were chosen. Six successive replicate determinations of each concentration were carried out by using the recommended procedure. The results of the study are summarized in Table 3 . The relative standard deviation in the range $1-2.2 \%$ and the percent recovery from 99.95 to $101.06 \%$ can be considered acceptable. For additional confirmation of the accuracy and precision of the proposed method, the standard addition method was performed by adding a known amount of pure drug to the preanalyzed dosage form. The results were reproducible with low standard deviation and the mean recovery range was 99.3-99.6\% (Table 4). Moreover, the results summarized in Table 4, suggest that common additives and excipients commonly present in pharmaceutical formulations, did not interfere with the determination.

Table 3. Precision and accuracy of the proposed method

\begin{tabular}{ccccc}
\hline \multicolumn{2}{c}{$\mathrm{CP}\left(\mu \mathrm{g} \mathrm{mL} \mathrm{m}^{-1}\right)$} & $\mathrm{S}\left(\mu \mathrm{g} \mathrm{mL}{ }^{-1}\right)$ & $\mathrm{RSD}(\%)$ & $\mathrm{R}(\%)$ \\
\cline { 1 - 2 } Taken & $\begin{array}{c}{ }^{\mathrm{a}} \text { Found } \pm \\
t S N^{-0.5}\end{array}$ & & & \\
\hline 0.5 & $0.51 \pm 0.01$ & 0.01 & 2.2 & 101.1 \\
1.0 & $1.01 \pm 0.01$ & 0.10 & 1.3 & 100.6 \\
2.5 & $2.50 \pm 0.02$ & 0.02 & 1 & 100 \\
\hline
\end{tabular}

${ }^{\mathrm{a}}$ Mean $\pm 95 \%$ confidence limit, for $\mathrm{N}=6 ; \mathrm{t}=2.57=\mathrm{t}$-distribution for confidence level of $95 \%$ with $\mathrm{N}-1$ degrees of freedom S = Standard deviation; RSD = Relative standard deviation; $\mathrm{R}(\%)=$ percent recovery

Table 2. Comparison of the proposed method with existing spectrophotometric methods for the determination of captopril

\begin{tabular}{|c|c|c|c|}
\hline Reagents & Linear range $\left(\mu \mathrm{g} \mathrm{mL}^{-1}\right)$ & LOD $\left(\mu \mathrm{g} \mathrm{mL}^{-1}\right)$ & Ref. \\
\hline Potassium iodate in $\mathrm{HCl}$ medium $+\mathrm{CCl}_{4}$ & $120-520$ & - & 13 \\
\hline $\mathrm{Ce}(\mathrm{IV})$ & $0.1-1.3$ & 0.016 & 18 \\
\hline Fe(III)-bipyridyl & $2-20$ & - & 20 \\
\hline Excess of chloramine- $\mathrm{T}+$ indigocarmine & $0-5$ & 0.068 & 21 \\
\hline Sodium azide and $\mathrm{I}_{2}$ & $0.1-1.5$ & 0.02 & 24 \\
\hline $\mathrm{KMnO}_{4}$ - methylene blue & $0.4-12.5$ & 0.106 & 25 \\
\hline Excess bromate - bromide + methyl orange & $0.25-2.0$ & - & 27 \\
\hline $\mathrm{Fe}(\mathrm{III})($ excess $\mathrm{Fe}(\mathrm{II})+$ potassium ferricyanide) & $1-11$ & 0.04 & 28 \\
\hline Excess $\mathrm{KBrO}_{3}+$ celestine blue & $0.4-4$ & 0.13 & 29 \\
\hline 2,6-dichloroquinone-4-chlorimide (DCQ) in dimethylsulphoxide & $10-50$ & 0.66 & 30 \\
\hline $\mathrm{Cu}(\mathrm{II})+$ neocuproin & $0.3-3.0$ & 0.056 & 33 \\
\hline $\mathrm{Cr}(\mathrm{VI})+$ diphenylcarbazide & $0.08-3.5$ & 0.024 & This work \\
\hline
\end{tabular}


Table 4. Results of recovery study using standard-addition method

\begin{tabular}{|c|c|c|c|c|}
\hline \multirow{2}{*}{$\begin{array}{l}\text { Amount of captopril taken } \\
(\mu \mathrm{g})\end{array}$} & \multicolumn{2}{|c|}{$\mathrm{CP}(\mu \mathrm{g})$} & \multirow{2}{*}{$\begin{array}{l}\text { Amount of } \mathrm{CP} \text { added } * \pm \mathrm{S} \\
(\mu \mathrm{g})\end{array}$} & \multirow{2}{*}{$\begin{array}{c}\text { Recovery of CP added } \\
(\%)\end{array}$} \\
\hline & added & found & & \\
\hline 5.5 & - & 5.6 & - & - \\
\hline 5.5 & 5.5 & 11.1 & $5.5 \pm 0.3$ & 99.3 \\
\hline 5.5 & 11.0 & 16.6 & $11 \pm 0.4$ & 99.6 \\
\hline
\end{tabular}

* Mean of three measurements \pm standard deviation $(\mathrm{S})$.

Table 5. Determination of CP content in tablets of Captopril using the proposed and the official methods

\begin{tabular}{|c|c|c|c|c|}
\hline \multirow{2}{*}{ Drug formulation } & \multicolumn{2}{|c|}{ Found $^{\#}(\% \pm \mathrm{SD})$} & \multirow{2}{*}{ t-Value } & \multirow{2}{*}{ F-Value $\mathrm{e}^{\# \#}$} \\
\hline & Proposed method & Official method34 & & \\
\hline Captopril ( $25 \mathrm{mg} \mathrm{CP} /$ tablet) & $99.5 \pm 0.4$ & $99.5 \pm 0.2$ & $0.42(2.20)$ & $4.00(5.05)$ \\
\hline
\end{tabular}

"Values are mean of six determinations. "\#alues in paranthesis are the theoretical t- and F- values for $95 \%$ confidence limits.

\section{Application}

The proposed method was applied for determination of $\mathrm{CP}$ in pharmaceutical tablet formulation. The results obtained by the proposed method were compared statistically with a HPLC method. Since the HPLC method used in this experiment was adapted from that described in the official USP monograph ${ }^{34}$ only the linearity of the methods was checked in the $6-13 \mathrm{mg} \mathrm{mL}^{-1}$ range for captopril. This range was chosen in order to cover the range of concentrations used to compare the performance of the proposed method with that of an official method. The study of the linearity for HPLC determination of captopril yield a linear range of $7.5-12.5 \mathrm{mg} \mathrm{mL}^{-1}$, a linear regression equation: $y=5.87 \mathrm{E}-7+1.74 \times$ and the correlation coefficient: 0.9992 . The results obtained revealed no significant difference in performance between the two methods regarding accuracy (according to t-test) and precision (according to F-test) (Table 5).

\section{CONCLUSION}

Although a number of spectrophotometric methods are available for the determination of captopril, these generally have drawbacks. The proposed method is characterized by its sensitivity, which permits the determination of a concentration as low as $0.08 \mu \mathrm{g} \mathrm{mL}^{-1} \mathrm{CP}$, and also by the simplicity of the procedure and reliability of results. Furthermore, the DPC as an analytical reagent is inexpensive and available from any analytical laboratory. The proposed method can be applied in quality control laboratories for the routine analysis of $\mathrm{CP}$ in raw material and pharmaceutical formulations.

\section{REFERENCES}

1. Prior, J. A. V.; Santos, J. L. M.; Lima, J. L. F. C.; Anal. Chim. Acta 2007, $600,183$.

2. Mazurek, S.; Szostak, R.; J. Pharm. Biomed. Anal. 2006, 40, 1225.

3. El-Brashy, A. M.; Acta Pharm. Hung. 1995, 65, 91.

4. Ensafi, A. A.; Hajian, R.; Ensafi, A. A.; Hajian, R.; J. Braz. Chem. Soc. 2008, 19, 405 .

5. Riberio, P. R. S.; Santinia, A. O.; Pezza, H. R.; Pezza, L.; Eclet. Quim. 2003, 28, 39.

6. Fraga, J. M. G.; Abizanda, A. I. J.; Moreno, F. J.; León, J. H. A.; Talanta 1998, 46, 75 .

7. Lourenção, B. C. L.; Marcolino-Junior, H.; Fatibello-Filho, O.; Quim. Nova 2008, 31, 349.

8. Koricanac, Z.; Jovanovic, T.; Stankovic, B.; Pharmazie 1995, 50, 299.
9. Hillaert, S.; van den Bossche, W.; J. Pharm. Biomed. Anal. 1999, 21, 65.

10. Wronski, M.; J. Chromatogr., B: Anal. Technol. Biomed.Life Sci. 1999, $676,29$.

11. Schmidt Jr., E.; Melchert, W. R.; Rocha, F. R. P.; Quim. Nova 2011, 34, 1205.

12. Liu, Y. C.; Wu, H. L.; Kou, H. S.; Chen, S. H.; Wu, S. M.; Anal. Lett. 1995, 28, 1465 .

13. Russell, J.; McKeown, J. A.; Hensman, C.; Smith, W. E.; Reglinski, J.; J. Pharm. Biomed. Anal. 1997, 15, 1757.

14. Franklin, M. E.; Addison, R. S.; Baker, P. V.; Hooper, W. D.; J. Chromatogr., B: Anal. Technol. Biomed. Life Sci. 1998, 705, 47.

15. Khedr, A.; El-Sherief, H.; Biomed. Chromatogr. 1998, 12, 57.

16. Tache, F.; Farca, A.; Medvedovici, A.; David, V.; J. Pharm. Biomed. Anal. 2002, 28, 549.

17. Liu, Y. L.; Wu, H. L.; Kou, H. S.; Chen, S.; Wu, S. M.; Anal. Lett. 1995 , 28,1465 .

18. El-Didamony, A. M.; J. Chin. Chem. Soc. 2009, 56, 755

19. El Reis, M. A.; Abou Ahia, F. M.; Kenaaway, I. M. M.; J. Pharm. Biomed. Anal. 2000, 23, 249.

20. Askal, H. F.; Talanta 1991, 38, 1155.

21. Basavaiah, K.; Nagegowda, P.; Bulg. Chem. Commun. 2003, 35, 48.

22. Basavaiah, K.; Chandrashekhar, U.; Swamy, J. M.; Charan, V. S.; Prameela, H. C.; Oxid. Commun. 2003, 26, 432.

23. Basavaiah, K.; Nagegowda, P.; Oxid. Commun. 2004, 27, 203.

24. El-Shabrawy, Y.; El-Enany, N.; Salem, K.; Il Farmaco 2004, $59,803$.

25. Shama, S. A.; Amin, A. E. S.; Omara, H.; J. Quant. Spectrosc. Radiat. Transfer 2006, 102, 261.

26. Basaviah, K.; Nagegowda, P.; Oxid. Commun. 2004, 27, 186.

27. Rahman, N.; Singh, M.; Hoda, N.; Il Farmaco 2005, 60, 569.

28. Rahman, N.; Anwar, N.; Kashif, M.; Hoda, N.; Acta Pharm. 2006, 56, 347.

29. Sastry, C. S. P.; Rao, S. G.; Naidu, P. Y.; Srinivas, K. R.; Anal. Lett. 1998, 31, 263.

30. El-Enany, F.; Belal, M. R.; Int. J. Biomed. Sci. 2008, 4, 147.

31. Wang, S. L.; Wang, M.; Li, Q. M.; Chin. Chem. Lett. 2009, $20,88$.

32. El-Didamony, A. M.; Erfan, E. A. H.; Spectrochim. Acta, Part A 2010, $75,1138$.

33. Gouda, A. A.; Amin, A. S.; Arabian J. Chem. 2010, 3, 159.

34. The United States Pharmacopeia, USP 30, The United States Pharmacopeial Convention, Rockville, 2007.

35. Bose, M.; Anal. Chim. Acta 1954, 10, 201.

36. Timmins, P.; Jackson, I. M.; Wang, Y. I.; Int. J. Pharm. 1982, 11, 329.

37. IUPAC (International Union of Pure and Applied Chemistry); Spectrochim. Acta, Part B 1978, 33, 241. 